\title{
Cutaneous Fibrous Histiocytoma, Cellular Variant
}

National Cancer Institute

\section{Source}

National Cancer Institute. Cutaneous Fibrous Histiocytoma, Cellular Variant. NCI

Thesaurus. Code C49078.

A morphologic variant of cutaneous fibrous histiocytoma characterized by the presence of spindle-shaped fibrohistiocytic cells and increased cellularity. 